\title{
Championing processes and the emergence of industrial symbiosis
}

Kokoulina Liudmila, Ermolaeva Liubov, Patala Samuli, Ritala Paavo

This is a Post-print version of a publication

published by Routledge

in Regional Studies

DOI: $10.1080 / 00343404.2018 .1473568$

Copyright of the original publication: () 2019 Informa UK Limited

Please cite the publication as follows:

Kokoulina L. Ermolaeva L., Patala S., Ritala P. (2019). Championing processes and the emergence of industrial symbiosis. Regional Studies, Vol 53, Issue 4. p. 528-539. DOI: 10.1080/00343404.2018.1473568 


\title{
CHAMPIONING PROCESS AND THE EMERGENCE OF INDUSTRIAL SYMBIOSIS
}

\author{
Published in Regional Studies \\ https://doi.org/10.1080/00343404.2018.1473568 \\ Liudmila Kokoulina* \\ Research fellow \\ Graduate School of Management, St. Petersburg State University \\ St. Petersburg, 199004, Russia, Volkhovskiy Pereulok, 3 \\ Tel: +7 8123293234 \\ e-mail: 1.kokoulina@gsom.pu.ru \\ *corresponding author \\ Liubov Ermolaeva \\ Research fellow \\ Graduate School of Management, St. Petersburg State University \\ St. Petersburg, 199004, Russia, Volkhovskiy Pereulok, 3 \\ Tel: +7 8123293234 \\ e-mail: l.a.ermolaeva@gsom.pu.ru \\ Samuli Patala \\ Postdoctoral researcher \\ Aalto University School of Business, Aalto, Finland \\ P.O. Box 11000, FI-00076 Aalto, Finland \\ Tel: +358 504403450 \\ e-mail: samuli.patala@aalto.fi \\ Paavo Ritala \\ Professor of strategy and innovation \\ School of Business and Management \\ Lappeenranta University of Technology (LUT) \\ P.O.Box 20, FI-53851 Lappeenranta, Finland \\ Tel: +358408335852 \\ e-mail: ritala@lut.fi
}

\begin{abstract}
Industrial symbiosis is an important concept for regional development in which industrial organizations seek to utilize one another's outputs and inputs, reduce waste and achieve economic benefits. Though the technical details of this phenomenon are well known, the roles of key individuals and, particularly, their championing processes remain unclear. The current paper includes a pre-study of a national industrial symbiosis system, followed by an in-depth case study of a regional industrial symbiosis related to heat reuse. The findings reveal novel implications concerning how champions facilitate collaboration among regional organizations and other stakeholders, leading to the emergence of industrial symbiosis.
\end{abstract}

Keywords: industrial symbiosis, case study, championing, champion, regional development, energy

Subject classification codes: R11, Q57 


\section{Introduction}

Organizations are under increasing pressure to create more sustainable practices and operations in their local regional contexts. In this regard, industrial symbiosis (IS) has emerged as an important concept for regional development (e.g. Gibbs, Deutz, \& Proctor, 2005; Deutz \& Gibbs, 2008), in which organizations exchange material and resource flows in such a way as to minimize waste and create mutual benefits for all actors. IS is a key approach to building a circular economy, with potential to unlock up to $\$ 4.5$ trillion in GDP growth globally by 2030 (Lacy \& Rutqvist, 2016). The concept is defined as 'engaging traditionally separate industries in a collective approach to competitive advantage involving physical exchange of materials, energy, water and by-products' (Chertow, 2000, p. 330). Therefore, IS is fundamentally tied to regional development, since it is inherently related to the social, technical and political arenas.

Previous research on IS has focused primarily on the technical aspects of material flows, waste management and resource efficiency (Chertow, 2000). Other streams have begun focusing on management processes on organizational and network levels (for a review, see Walls \& Paquin, 2015). However, little understanding remains of individual-level processes and the role of individuals in regional IS initiatives. Such processes are vital, since the reuse of excess materials in IS, while potentially profitable, often falls outside of a firm's core business strategies. Thus, visionary and far-sighted individuals are needed to push forward new types of regional interaction, including complex relational efforts in which individual-level agency plays a key role (as suggested in inter-organizational and championing literature, e.g. Klerkx \& Aarts, 2013).

To address the above-mentioned research gap, this paper analyzes the roles of champions and championing in the emergence of IS. Champions are individuals who stand out in their organizations through their innovativeness, willingness to take risks and transformational leadership styles (Howell \& Higgins, 1990). Such individuals typically possess technical competence, knowledge about the company, knowledge about the market and political astuteness (Chakrabati, 1974). Champions play an important role in explaining how IS relationships and systems emerge. We also focus on championing processes, and the different types of individual-level agency of champions within the organizational context.

The empirical part comprises a pre-study of a national IS network, followed by an indepth case study of a regional IS system focused on the use of excess heat from a data centre's energy production process. The findings indicate that the process of championing is strongly linked to roles and activities that change over time. Championing processes are also contextual, as they require a strong organizational and institutional fit to be successful. Our results contribute to the IS and the regional development literature by highlighting the individual level of analysis and illustrating the diversity of championing roles and processes.

\section{Theoretical background}

\subsection{Industrial symbiosis and regional context}

IS focuses on the cooperative management of resource flows through firms' networks. It involves the broader field of industrial ecology, which examines the sustainability of material and energy flows through industrial systems. IS seeks to facilitate the physical exchange of materials, energy, water and by-products (Chertow, 2000), as well as the 
exchange of non-material resources, such as knowledge and expertise (Lombardi \& Laybourn, 2012). Companies can also share utilities, such as energy, water and wastewater treatments, and services, such as transportation, landscaping and waste collection (Ashton, 2008). The main drivers of IS are the economic and environmental benefits realized by the mutual exchange of complementary resources (e.g. Behera et al., 2012; Tudor et al., 2007), as well as the tightening of waste management regulations (Doménech \& Davies, 2011). In a wider sense, IS aims to support sustainable strategies in industrial development and the implementation of modern technologies, ecoinnovations and cultural change in organisations (Behera et al., 2012; Lombardi \& Laybourn, 2012; Mirata \& Emtairah, 2005).

Geographic proximity is considered central to IS because it facilitates material exchanges, transportation, trust and collaboration (Lombardi \& Laybourn, 2012; Taddeo et al., 2012), as well as the sharing of information and norms within social networks (Ashton \& Bain, 2012). This geographic focus is reflected in the other commonly used term for IS networks: eco-industrial parks (Hewes \& Lyons, 2008;; Tudor et al., 2007). Repeated interactions and geographical proximity often lead to the creation of shared norms that influence actors' behaviours and patterns of relationships (Ashton \& Bain, 2012). There are many examples of successful IS networks globally (Walls \& Paquin, 2015). Many countries, including e.g. European countries and China, have also implemented nationallevel programs to promote IS (Gibbs \& Lintz, 2016, Liu et al., 2012; Paquin \& HowardGrenville, 2012).

\subsection{Institutional, network, organizational and individual levels of analysis}

Institutional perspectives to IS have examined the impacts of regulations, norms and cultural-cognitive aspects on the emergence and development of IS networks. For instance, supportive regulations (Doménech \& Davies, 2011; Gibbs \& O’Neill, 2017) and informal norms (Ashton \& Bain, 2012) have been found to be especially important for the emergence of IS networks and their institutional capacity (Boons \& Spekkink, 2012). Institutionalization in later-stage IS networks is often characterized by the existence of a formal organization in charge of facilitating the network's activities (Chertow \& Ehrenfeld, 2012).

Network-level analyses focus on relationships among industrial firms from different industries, as well as governmental and societal organizations involved as knowledge providers or coordinators (Paquin \& Howard-Grenville, 2013). The geographical proximity of the involved actors leads to embeddedness, such that IS relations are often tied to existing informal relations among actors (Doménech \& Davies, 2011) and a 'close mental distance' (Ashton \& Bain, 2012). IS networks develop over time through three primary mechanisms: 1) self-organization, 2) facilitation by organisations or individuals and 3) central planning (see e.g. Chertow \& Ehrenfelt, 2012; Paquin \& Howard-Grenville, 2012; Boons, Chertow, Park \& Spekkink, 2017). While many studies on IS development have focused on the self-organization vs. central planning dichotomy (Baas, 2011), more recent work has emphasized facilitated networks, in which a coordinator's main task is to find potential partners among participating companies (Paquin \& Howard-Grenville, 2012, 2013). For example, the UK's National Industrial Symbiosis Programme (NISP) facilitates the formation of IS relationships by sharing information and analysing potential exchanges among participating companies (Doménech \& Davies, 2011).

The organizational and individual levels have been studied much less than the 
institutional and network levels. Organizational-level studies have typically examined IS activities by assessing the benefits or barriers for individual firms for engaging in IS (Chertow \& Miyata, 2011), or on how to achieve IS in single facilities (Mulrow et al. 2017). However, there is a considerable lack of research on, for example, how firms decide to engage in IS (Walls \& Paquin, 2015). Individual-level studies have thus far been scarce. Current research has identified the importance of champions for the development of IS networks (Hewes \& Lyons, 2008). However, as championing is often a complex process involving multiple championing roles and interactions (Klerkx \& Aarts, 2013), this topic remains rather under-explored. The next subsection will focus on championing in IS in more detail.

\subsection{Championing processes in industrial symbiosis}

The term 'champion' was originally introduced by Schon (1963) and later further developed by Witte (1973). Since that time, there has been a considerable interest in the role of individuals in promoting innovation (Fichter, 2009; Rothwell, 1992). In general, champions are defined to be individuals who actively promote new innovations in their organizations, take risks in the innovation process, possess in-depth knowledge regarding the innovation and exhibit a transformative leadership style (Chakrabati, 1974; Howell \& Higgins, 1990). The activities and processes in which champions engage to promote innovations are commonly called 'championing'. From an organizational perspective, IS can be perceived as either a business model innovation (Foss \& Saebi, 2017) or an architectural innovation (Henderson \& Clark, 1990); therefore, the championing literature can provide a useful foundation to study the role of key individuals in IS emergence.

Literature has identified various champion roles, distinguishing among power, expert, process and network champions (Klerkx \& Aarts, 2013). A power champion contributes to the process through hierarchical power. An expert champion provides expert knowledge to promote the innovation (Ficther, 2009; Witte, 1973). A process champion possesses 'organizational knowledge' that helps to arbitrate between the technical and economic worlds (Hauschildt, 1999). Lastly, relationship or network champions encourage the innovation process through internal and external business relationships.

While the actions of individuals have received little attention in the research on IS, some scholars have examined championing in the IS context (Hewes \& Lyons, 2008; Isenmann, 2002). For instance, Hewes and Lyons (2008) found champions to be key individuals who have a significant influence on IS development. They noted that champions are able to bring together various actors and motivate them to become personally involved in IS projects by building trust with people and inspiring them through personal values. They also identified that it is important for champions to be embedded in the local community in which the IS project is taking place.

Thus far, the knowledge on IS championing has emphasized the network championing role, since IS networks typically require cross-industry relations. However, there is a need to build a more comprehensive view of the potentially complex championing processes and the multiple champion roles present in IS (Walls \& Paquin, 2015). Firstly, IS projects commonly require specialized technical expertise (e.g. for waste reprocessing), suggesting a need for expert champions. IS also often receives and is embedded in governmental and political support (Salmi \& Toppinen, 2007), suggesting a need for process (administrative) champions. Moreover, self-organized IS networks typically develop through different stages (Chertow \& Ehrenfeld, 2012), and it is highly likely that, 
during this development process, championing processes are dynamic.

\section{Methodology}

\subsection{Research design and data collection}

Our research design included a pre-study of 12 organizations and second, a single case study of IS emergence. The role of the pre-study was to create an initial understanding of the phenomenon, which was used in the more focused inquiry conducted in the main study.

Single case study methodology is particularly suitable for studying inadequately understood phenomena (e.g. Yin, 2014), such as championing in IS. According to Lervik (2011), focusing efforts on one research site allows the implementation of complex multilevel research designs. Our main units of analysis are organizations and relationships, which are difficult to access and structurally complex. Thus, we see the single case study research as an appropriate research method for studying the formation of IS relationships. Figure 1 summarizes our research design.
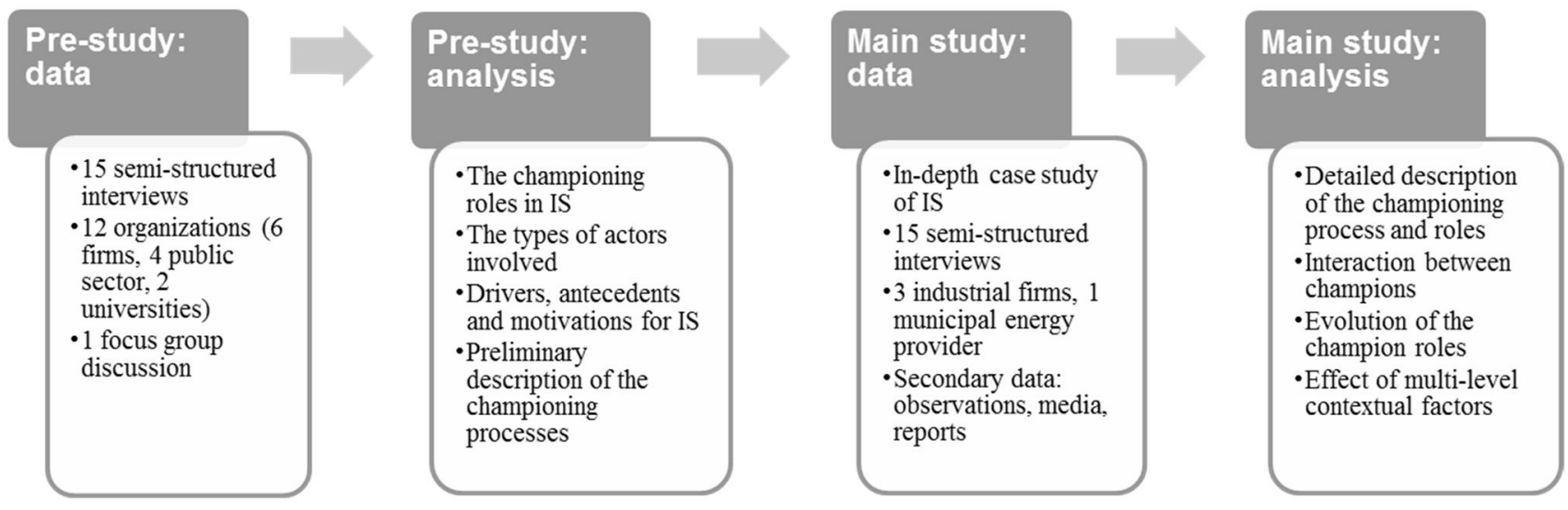

\section{Figure 1. Research process}

The primary data include altogether 30 semi-structured and in-depth interviews. The secondary data includes on-site observations, reports and media news. As a result of the data analysis, we provide a detailed description of the championing process and roles, interactions among champions, the evolution of the champion roles and the effects of multilevel contextual factors.

Pre-study data were collected during 2014 from Finland's emerging national IS network. The interviews focused on key personnel from organizations involved in designing and 
developing a national programme to facilitate IS in Finland. Altogether, 15 semistructured interviews were conducted in 12 different organizations. The organizations included four public sector organizations involved in developing the program, six firms that had IS initiatives prior to the programme and acted as anchor tenants in local networks and two universities/research centres that were involved as expert partners.

Main study data were collected between 2015 and 2016 through 15 in-depth and semistructured interviews, conducted by two researchers. Interviews were chosen as the data collection method because interviews are particularly well suited to studies requiring an understanding of deeply rooted phenomena or experiences (Eriksson \& Kovalainen, 2008). In-depth interviews were used to gain an overall understanding of the case context and the phenomenon, and semi-structured interviews to focus attention on the important topics related to the phenomenon. The interviewees talked very openly about their experiences and opinions related to the studied phenomenon. Six interviews were conducted by phone and video conference, and the rest were conducted in person. The informants came from four key companies within the IS (heat seller, buyer, technology provider and architectural agency) and included main decision makers influencing the project during various phases of the case. The details of the empirical data for both studies are listed in the Online Appendix.

\subsection{Case description}

The pre-study focused on an emerging IS programme in Finland that seeks to facilitate valuable waste and byproduct exchanges among industrial firms, the Finnish Industrial Symbiosis System (FISS). One of the barriers to IS is that it often requires cross-industry collaboration, and firms are often focused on their own supply chains and industries. FISS aims to address this barrier through several key activities: holding cross-industry workshops to identify new IS opportunities, maintaining a resource information database, raising IS awareness through seminars and case stories as well as forming a network of technical experts to facilitate IS projects. The network is coordinated on the national level by a governmentally-owned organization specializing in energy and environmental services. FISS also includes designated regional-level coordinators, including both public and private sector organizations, which are in charge of organizing the network activities within a specific region.

The main study built on the results of the pre-study and the theoretical background. It focused on a single case study of a data centre for excess heat reuse in regional energy production. It included four organizational actors (see Online Appendix for detailed case company descriptions), through which the roles of individual champions and related processes that facilitate the emergence of regional IS were examined. The focus was on the hub company and the key individuals, and it sought to demonstrate the relevant processes, roles and relationships.

The case began in 2012. Between 2012 and 2015, the Russian information technology (IT) company Yandex set up a data centre in Mäntsälä, a small city located about 60 kilometres north of Helsinki, Finland. This data centre supported a partnership between the technology provider and a local energy supplier to reuse waste heat from the data centre and sell it to the local energy company to warm local homes. Yandex data centres generate heat, which is collected and directed along the district heating network to Mäntsälä households. The initial collected waste heat could power approximately a thousand households. The project represented the first in the world at this scale. The 
collected waste heat reduces the carbon dioxide emissions of the district's heating by up to $40 \%$. This is a significant achievement, since it corresponds to the EU objective of reducing emissions by 2030 . Heat recycling is good for the environment and, in the long term, will also improve the competitiveness of district heating. Currently, up to $50 \%$ of the district's natural gas usage can be replaced by recycled heat. Furthermore, in the case of the data centre, waste heat recovery can be increased in the future, with the eventual goal of completely replacing natural gas.

\subsection{Data analysis}

Inductive analysis utilizes emergent coding from interview data, and deductive analysis utilizes coding guided by a literature review. The goal of the both types of coding is to find the themes relevant to the study. For these purposes, the present research adopted the coding approach proposed by Glaser and Strauss (1999), borrowed from grounded theory. The general coding scheme consists of four categories: (1) the phenomenon under study, (2) the conditions related to that phenomenon (e.g. context conditions, intervening structural or causal conditions), (3) the actions and interactional strategies directed at managing or handling the phenomenon and (4) the consequences of the actions/interactions related to the phenomenon. This general coding scheme was adopted for the overall study. For the pre-study, we focused on the roles and inter-organizational relations of the organizations in the network. For the main study, we focused on the external factors, motivation, roles, critical events in the process, as well as on personal relationships.

\section{Research findings}

\subsection{Championing roles and organizational types}

In the pre-study, we focused on exploring the different championing roles within the IS context. The FISS network involved cross-sectoral collaboration spanning public, private and academic sectors. Four main organizational types involved in championing IS included public sector organizations, businesses, local authorities and research organizations. These were all involved in actively facilitating IS, but for different reasons, such as new business opportunities, environmental sustainability, local industrial development and job creation.

The primary goal of public sector organizations is to support societal development by improving the sustainability of industrial firms. In Finland, two public sector organizations had primarily responsibility for forming a national model for IS development. Business actors typically had core businesses related to IS. Such firms included, for example, technical consulting organizations, suppliers of technologies for the reprocessing of materials and active utilizers of byproducts. Local authorities sought to support regional development and develop industrial clusters through the novel approach of IS. They mobilized knowledge resources, facilitated networking among firms, helped firms find financial resources and facilitated the permitting process for IS opportunities. Lastly, research organizations played an important role as expert partners in developing IS networks. Their primary goal is generating and disseminating new knowledge regarding IS.

The pre-study also identified four main championing roles. The first is focused on influence and power championing. These champions use power derived from a position of authority or personal influence to steer the network's actions. The actors in this role were commonly local authorities or business representatives. For local authorities, their 
position allowed them to develop IS activities through their legitimate role in regional development. For businesses, high levels of personal influence allowed these champions to find partners for IS activities, and their power within their own organizations allowed them to prioritize internal business activities. The public sector organizations also had power and authority as programme coordinators.

Networking and collaboration champions focused on addressing one of the key barriers to IS: crossing industrial boundaries. The public sector organizations played a key role in this championing process. They held collaborative workshops for industrial firms in different regions in Finland with the aim of facilitating cross-industrial relations by having firms list their available unused resources. Local authorities held similar networking sessions for local firms, but these were typically more informal in nature, as many involved individuals who already knew each other due to geographical proximity. Some of the firms also played a minor role as network champions.

Technology and expertise champions had access to the technological resources, knowledge and know-how required to realize identified IS opportunities. The two key organizational types in this role were research organizations and businesses. Research organizations were typically involved in development and research projects and had access to knowledge (e.g. technological, legal, managerial) and data (e.g. material flow analyses and material databases) capable of helping to realize IS opportunities. Businesses filled this role as technology suppliers who provided the technology necessary to reprocess materials. They also acted as middlemen by purchasing waste/byproducts from one firm and selling them to other firms.

Lastly, institutional champions primarily facilitated the regulatory, legal and permitting aspects of IS. This role was primarily played by local authorities, who facilitated and helped with permitting processes. National regulations related to waste reprocessing were often mentioned as possible barriers to IS, but no institutional champions on the national level were evident. However, the public sector organizations mentioned that they collect data on regulatory barriers to IS in an attempt to influence political decision-makers, suggesting that these organizations do play a minor role as institutional champions.

The FISS network covered a large geographical area and included multiple regional subprojects, allowing us to get a wider view of championing IS. The pre-study provided us with preliminary understanding on the types of organizations and their roles in championing industrial symbiosis. In order to explore the dynamics of the championing process and the role of individuals in more detail, we undertook an in-depth case study of a single IS project (i.e. the main study), results of which are discussed in the remainder of this paper.

\subsection{Main stages of industrial symbiosis emergence}

Figure 2 demonstrates the three main stages of the Yandex data centre heat reuse project: idea genesis, mobilization and focused legitimization and broad legitimization. These stages involved different champion roles, with individual-level (i.e. champion related) as well as contextual factors (e.g. organizational environment and culture, macro environment). Three organizations were involved in the IS project. These were Yandex, the owner of the data centre; Mäntsälän Sähkö Oy (MSO), the local energy provider; and Calefa, a technology company. In addition, some other actors, such as local authorities and associations, played minor roles in different stages of the project. 
CHAMPIONS` ACTIONS

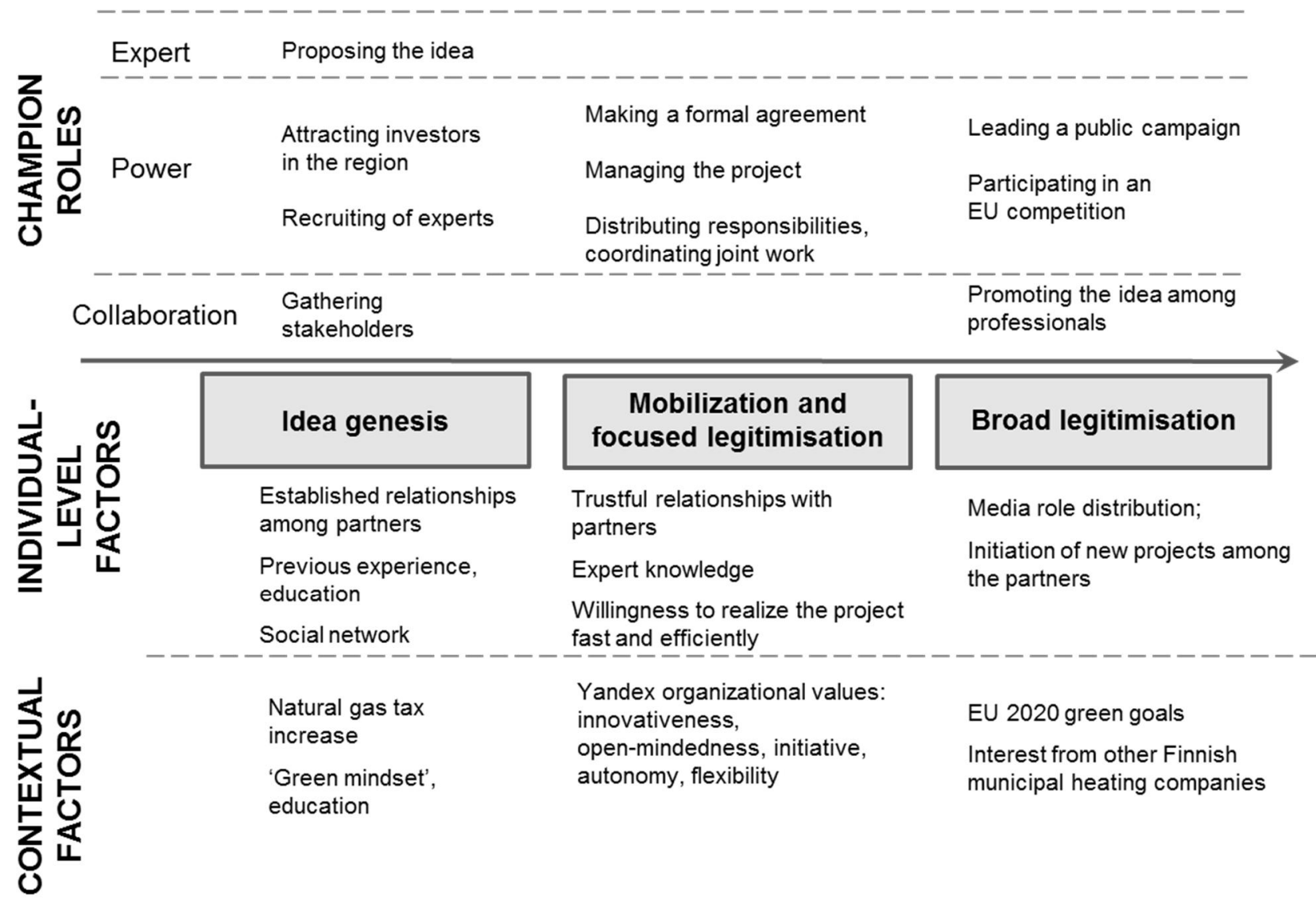

\section{Figure 2. Stages of the project within the context}

The idea genesis stage involved setting up the foundation. The idea of heat reuse had already been raised during an initial meeting between Yandex management and Mantsälä authorities. It was a minor issue to Yandex, as it was concentrating mostly on the choice of location and was under significant time pressure to make a decision. However, a representative at the institutional level (Mantsälä Business Development CEO) remarked that this represented an added bonus to their investment offer. Yandex chose Mantsälä as the location for the Data Centre (DC) and hired a Head of DC to govern all DC operations. The Head of DC was the key visionary presenting the idea to Yandex management based on his previous experience and expertise in the field.

The CEO of Mäntsälän Sähkö Oy (MSO) saw an opportunity to use excess heat for district heating and hired a specialist with a suitable background to support the project. In other words, MSO solicited heat reuse expertise even before Yandex entered the stage and actively developed the discussion around the idea. MSO was interested in developing a heat reuse project because of increased gas prices and the need to diversify energy sources. In addition, the young specialist's diploma had focused on DC heat reuse opportunities; therefore, he was able to suggest a heat reuse model as an innovative solution for MSO. To summarize, several different contextual (e.g. natural gas price increases, environmental awareness in Finland) and individual factors converged to support the launch of the IS project. 
At the beginning of the second stage, mobilization and focused legitimization, there were three main problems. First, convincing Yandex top management that the IS project was necessary required time and effort. Only the Head of DC, with his expertise, could convince others that the project was not risky, would not affect core operations and would not negatively affect the project schedule of the DC itself. Second, since the Head of DC was hired after the DC design had already been done by Dutch company Royal Haskoning DHV, it was difficult to integrate the heat reuse solution into the existing DC design. To accomplish this, Calefa and Yandex engineers had to collaborate. The third related challenge was time pressure. When Calefa stepped into the project, it had only 1.5 months to implement and design the IS solution. Nevertheless, this stage progressed quickly, thanks to the trusting relationships and mutual interest among the partners, as well as flexibility and an openness to new ideas in Yandex's organizational culture. By the completion of this second stage, the IS project had been recognized as innovative and had attracted considerable public attention. Ongoing opportunities were also identified in using excess heat in collaboration with other partners.

Finally, at broad legitimization stage, the IS project received public recognition on the regional, national and even EU level. Yandex's Head of DC and MSO's CEO became reference persons for the media and held talks at numerous conferences to promote the project as a successful example of IS. Thus, the project catalyzed other similar projects in a broader area through information dissemination and the technology provider Calefa, who was able to recommend similar innovative decisions to other clients. For example, in its next DC, which will be constructed in another region of Russia, Yandex aims to develop similar heat reuse projects with local partners and the technological provider from Finland.

During each stage, key actions characterizing champions' roles were identified (see Figure 2). Moreover, realization of each stage is affected by individual-champion-related and contextual factors. Such factors as previous experience, knowledge and social network were important for idea genesis. Power and collaboration champions were able to create a team of equally motivated partners for generation and pursuing the IS idea. In addition, external events such as increasing gas taxes pushed all sides to find beneficial solution. At the mobilization and focused legitimization stages partners' trustful relationships and common vision enabled smooth and efficient idea implementation, while power, collaboration and expert champions together coordinated the project. Yandex organizational culture supporting autonomy, initiative-taking and proactiveness created favourable conditions without excessive administrative barriers. At the broad legitimation stage, power and expert champions created public and officials interest to the project thanks to continuing cooperation among partners. Furthermore, as the project corresponds to EU goals and general good attitude towards green production, IS project was welcomed by authorities, institutions and broader public.

\subsection{Championing process in different domains}

It was further found that there were three domains in which championing processes took place: organizational, network and institutional. Within these domains, the three championing roles as identified during the pre-study were examined: 1) power, 2) collaboration and 3) expertise. It is noteworthy that the institutional championing initially identified in the pre-study did not appear to play a salient championing role in the main study, but, rather, served as a domain within which some of the other roles were exercised. The champions' actions and roles in different domains and across different stages of IS emergence are described in Table 1, along with representative quotes. 
Table 1. Champion's roles and supportive data (1 - idea genesis stage; 2 - mobilization and focused legitimisation; 3 - broad legitimisation)

\begin{tabular}{|c|c|c|c|c|c|c|c|c|c|}
\hline & Champion & Information source & Quote & & om & & & Rol & \\
\hline & & & & 竞. & 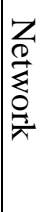 & 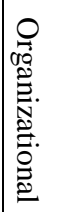 & 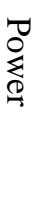 & 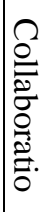 & 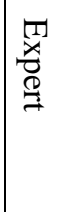 \\
\hline & DC, Manager & DC, Manager & $\begin{array}{l}\text {... when I joined I said 'ok, now it`s time to develop this project again and this is the right time to do it on time of the } \\
\text { construction'. }\end{array}$ & & & $\mathbf{\square}$ & & & $\mathbf{\square}$ \\
\hline & DC, Manager & Industry expert & He was a pro heat reuse guy and he pushed it further in his organization. & & & [ & $\mathbf{\square}$ & & \\
\hline & DC, Manager & Head of DC Operations & This is totally his project. He managed it by himself, and we didn't intervene at all. & & & $\square$ & $\square$ & & \\
\hline & CEO, MSO & Manager, Calefa & The top-level administrator of municipality was key. He was able to build kind of thinking in municipality. & $\mathbf{\square}$ & & & $\mathbf{\square}$ & $\mathbf{\square}$ & \\
\hline & CEO, MSO & CEO, MSO & $\begin{array}{l}\text { We started to plan the concept already about five years ago, after we realized what is going to happen with natural gas } \\
\text { taxation, so when a data centre would consider situating in Mäntsälä, we would be ready. }\end{array}$ & $\mathbf{\square}$ & & & $\square$ & & \\
\hline & CEO, MSO & $\begin{array}{l}\text { CEO, Calefa } \\
\text { CEO, MSO }\end{array}$ & $\begin{array}{l}\text { The key person who wanted it was the director of MSO. He hired [the heat reuse specialist] to do that. } \\
\text { There were several persons involved in the negotiations. Basically, Yandex needed a confirmation from Moscow. From our } \\
\text { side, I could make the needed decisions myself. }\end{array}$ & & & 口 & - & & \\
\hline & Manager, Calefa & Industry expert & $\begin{array}{l}\text { Calefa did a big part of the project. They made all the calculation[s] and made [the] project suitable for Yandex. Calefa has the } \\
\text { best know-how in Finland and perhaps in the world. }\end{array}$ & & & $\boldsymbol{\square}$ & & & \\
\hline & CEO, MBD & CEO, MBD & $\begin{array}{l}\text { In the first meeting, I asked, 'What are your needs?' Then, I collected a technical group, water, building inspection, and all the } \\
\text { information on the same day. }\end{array}$ & $\mathbf{\square}$ & & & & $\square$ & \\
\hline
\end{tabular}




\begin{tabular}{|c|c|c|c|c|c|c|c|c|c|}
\hline \multirow{7}{*}{$N$} & DC, Manager & DC, Manager & $\begin{array}{l}\text { I just talked with my manager [Head of DC Operations], through couple of emails. Then, I met [another Yandex manager] on } \\
\text { some meeting, and we agreed on that. }\end{array}$ & & & $\mathbf{a}$ & & & $\mathbf{\square}$ \\
\hline & DC, Manager & DC, Manager & [About price negotiation,] it was me and, from MSO, [the CEO of MSO]. & & & $\mathbf{\square}$ & $\mathbf{\square}$ & & \\
\hline & DC, Manager & DC, Manager & I'm typically meeting everyone informally. ...Even with [the CEO of MSO], we met in the café. & & $\square$ & & & $\square$ & \\
\hline & CEO, Calefa & CEO, Calefa & $\begin{array}{l}\text { The will and trust from Yandex were big enough, so we moved fast.....And [the CEO of MSO] writes that they had some } \\
\text { considerations of this kind, and they knew that we could do it. }\end{array}$ & & $\mathbf{\square}$ & & & & \\
\hline & Manager, Calefa & Manager, Calefa & $\begin{array}{l}\text { There were quite a lot different kind[s] of interest organizations: project organizations, suppliers... so we had to work with all } \\
\text { of them in terms of schedule and constructions. }\end{array}$ & & $\square$ & & $\mathbf{\square}$ & & \\
\hline & CEO, MSO & Manager, Calefa & So it was the Mantsälä managing director who gave the total control, so he was the top guy in this project. & & & $\square$ & $\square$ & & \\
\hline & CEO, MSO & DC, Manager & $\begin{array}{l}\text { If you are [a] municipality or public company, there are certain rules [governing] how you choose the contractors. It's a very } \\
\text { strict process, and it [takes] a lot of time. }\end{array}$ & $\mathbf{\square}$ & & & 曰 & & \\
\hline \multirow{4}{*}{$m$} & DC, Manager & Head of DC Operations & $\begin{array}{l}\text { Now he gets well-deserved honour. He attends all the European conferences, and now he presents on behalf [of] not just [the] } \\
\text { project but the country. }\end{array}$ & [ & & & & & \\
\hline & CEO, MSO & CEO, Calefa & $\begin{array}{l}\text {...this prize that they [Mantsälä as a city] won on heat reuse. This project gained huge support. I don't know if it is subsidized, } \\
\text { but they received huge publicity from this. }\end{array}$ & $\mathbf{\square}$ & & & $\mathbf{\square}$ & & \\
\hline & DC, Manager & DC, Manager & $\begin{array}{l}\text { They (Yandex) believed now that this is big because it increased our visibility on [the] market and we are doing something } \\
\text { that was not done before. So the market value for Yandex was big. }\end{array}$ & & & $\mathbf{\square}$ & $\mathbf{\square}$ & & \\
\hline & CEO, Calefa & Head of DC Operations & We present this project, how it is good, and Calefa gets its part of this pie. So we can speak about partnership in this case. & $\square$ & & & $\mathbf{\square}$ & & \\
\hline
\end{tabular}


During the idea genesis stage, three interesting observations emerged. Firstly, organizational and institutional domains were critical at this stage, and power champions played a key role. Power champions were representatives of two major sides: Yandex and MSO (including, especially, the DC manager and MSO's CEO), which pushed for the IS idea and made it realistic. Secondly, we identified that MSO, the party most interested in realizing the project, was actively engaged in the institutional domain as a power and collaborative champion. Thirdly, expert championing was needed at this stage in the network domain to provide background technical expertise.

At the mobilization and focused legitimization stage, all champions were involved in the network domain (playing collaboration, expert and power champion roles), as this stage required joint work and considerable collaboration among the involved parties. In addition, the organizational domain was still represented by power champions who continued to push the project forward and to control its realization. The institutional domain was less important than the first stage. However, a power champion from the local energy provider was constantly present to address problems or regulatory questions. During the broad legitimation stage, the institutional domain became more critical. This stage comprised the majority of the actions and required the collaboration of power and expert champions from two organizations (Yandex and MSO). The DC Manager became an expert voice for the 'Invest in Finland' movement, promoting DC heat reuse (and Finland as a host country for data centres) at various global events. Similarly, the CEO of MSO shared his experience at industrial events following Mantsälä's receipt of the European award for 'best heat reuse project'.

In general, the analysis yielded were several important observations: Firstly, the champion of the core organization played different roles in all domains, whereas the two other champions retained one major role (Calefa: expert, MSO: power) in one or two domains. Additionally, champions were more active in different domains during different stages. Specifically, during the first and last stage, the importance of the institutional domain was emphasized, whereas the network domain was emphasized during the second stage. Furthermore, with respect to role distributions, the power champion dominated in all domains and all stages.

\section{Discussion and conclusions}

The findings highlight the importance of multiple champions and their repeated interactions during the championing process. The championing processes were dynamic, and the roles of individual champions and their domains of action shifted during the industrial symbiosis (IS) development. In this regard, we examined two types of actors: organizations and individuals.

Organizational actors, businesses, government agencies and research institutions all contribute to IS emergence and development. Together, government agencies and business representatives operate as influence and power champions using their bargaining capabilities and administrative resources. Moreover, both government agencies and businesses can achieve their particular goals of regional development and economic growth. Furthermore, as local authorities facilitate the regulatory and permitting aspects of IS, they become identified as institutional champions. Collaboration champions are also important players for IS emergence. Their main objective is to facilitate crossindustrial relations, which they pursue by organizing collaborative workshops and 
network meetings. Moreover, IS opportunities cannot be realized without expert champions, such as research organizations and businesses. To summarize, the organizational-level emergence and development of IS requires the cooperation of multiple actors functioning in different championing roles.

For individual actors, it is important to stress that IS emergence is a gradual and collaborative process that takes place across different domains: organizational, network and institutional. In the organizational domain, champions (including, especially, power champions) can encourage and realize projects from the inside. In the network domain, collaboration champions are needed at all stages. On institutional level, a power champion was present at all stages, a collaboration champion was present at the idea genesis stage and an expert champion was present at the broad legitimization stage. Overall, power champions dominate all stages and domains, indicating the crucial role of charismatic, active and enthusiastic individuals who engage other actors. Finally, although their role in the process of IS emergence is less visible, expert champions are also present in all domains and can share their experience and knowledge with others during the final broad legitimization stage, invoking further dissemination of the IS idea.

These findings complement previous literature where champions are seen as key individuals who are able to bring together various actors and inspire them to be involved in IS projects (Hewes \& Lyons, 2008). Our study illustrates how champions' motives were supported by the organizational (Yandex) and institutional (Mantsala municipality) environments. The interplay of these two contexts, coupled with motivations by individual champions provided the recipe for success in our case.

In the regional context, previous IS literature has highlighted the idea of the 'sprouting' of IS networks, in which one successful project can lead to other IS projects and, gradually, a network. The MSO CEO, for example, could promote heat reuse solutions at regional meetings of district heating specialists. Similarly, Calefa, as the first technological provider in this field, can use this case as illustrative for other partners and customers. In fact, since the development of the case, the idea of heat reuse has become more feasible and has diffused beyond regional borders. Thus, the broad legitimization stage can also be seen as a key for catalyzing new IS projects both within a region and across other regions. The overall process of IS emergence is shown in Figure 3. 


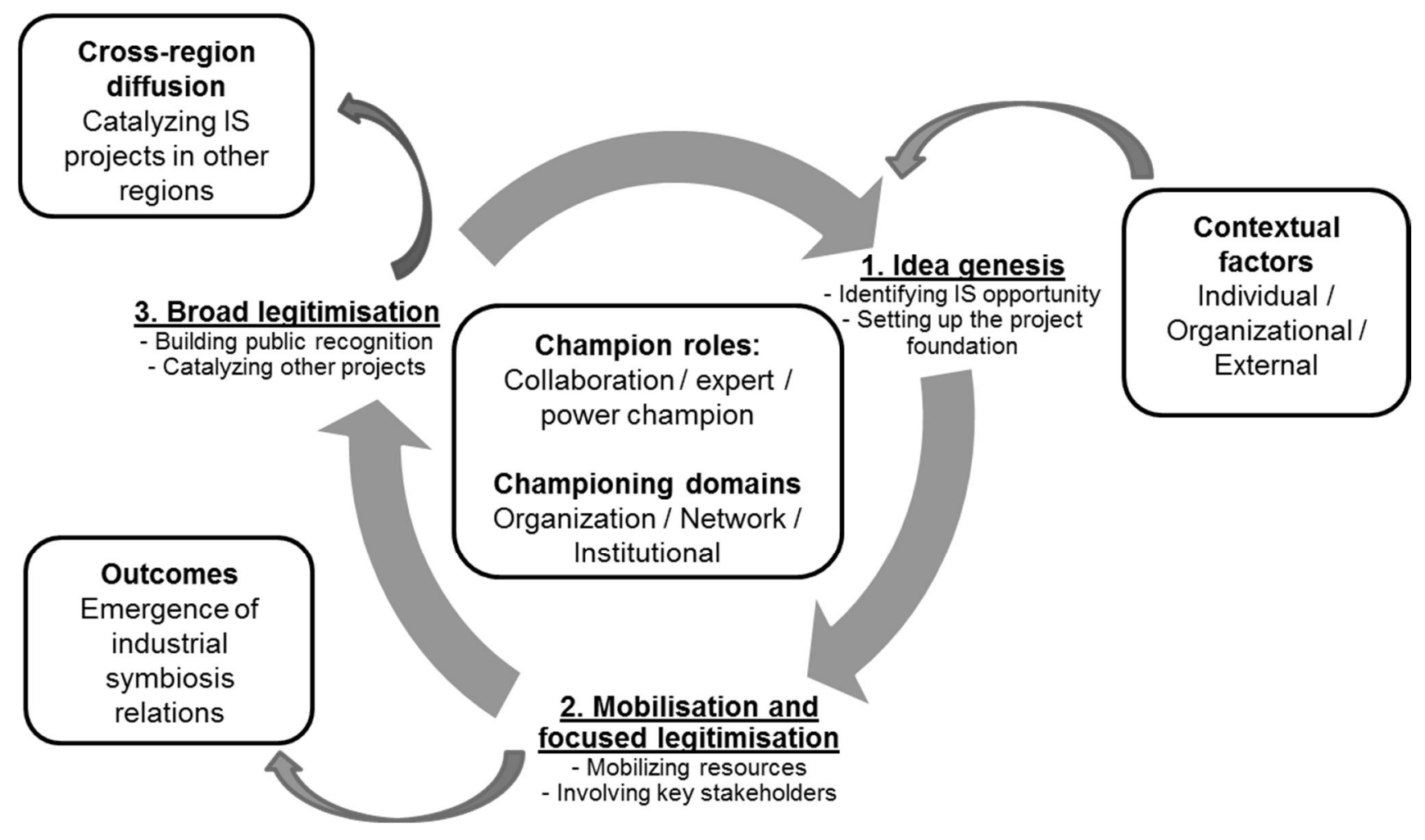

Figure 3. The process of IS emergence

\subsection{Theoretical implications}

Our study contributes the studies on IS facilitation and emergence by emphasizing the role of individuals, on which studies have been notably scarce (Walls \& Paquin, 2015). While the role of champions has been acknowledged (Hewes \& Lyons, 2008), our prestudy demonstrates champions' importance in a facilitated IS network across multiple scales (national and regional). Since many countries and regions are forming initiatives to facilitate IS, studies should focus not only on the typical organizational actors, such as coordinators or firms (e.g. Domenech \& Davies, 2011; Paquin \& Howard-Grenville, 2012), but also on identifying and recruiting the right champions (individuals) for IS. Moreover, our research sheds more light on the emergence of IS (Boons et al. 2017; Mulrow et al. 2017), by highlighting the role of individual agency.

Secondly, we elaborate the multifaceted roles played by IS champions, an area previously overlooked. The findings indicate that championing encompasses at different key roles: power, collaboration, expertise and institutional. Furthermore, individual champions can play multiple roles, as was the case in our main study. However, the personal characteristics and backgrounds required for championing roles differ considerably and it is unlikely that a single individual could effectively fulfil all of them. IS championing is, therefore, typically a collaborative effort among multiple individuals from different backgrounds. Furthermore, the findings demonstrate a dynamic view of the championing process (Klerkx \& Aarts, 2013). We found that though one champion can play both power and collaboration roles simultaneously, these roles typically operate on different levels and might change over time.

Finally, there is a growing body of literature examining sustainability in regional studies (Chang et al., 2016; Klooster \& Mercado-Celis, 2016; Truffer \& Coenen, 2012). This study examines the micro-foundations of such activities. A successful IS project with 
recognized sustainability benefits may spur other regional actors to consider similar initiatives. The literature recognizes the idea of sprouting IS networks (Chertow \& Ehrenfeld, 2012), in which successful projects may build capacity for further IS projects in the same region. Our findings suggest that influential individuals could build new relations and networks, mobilize resources and act as institutional facilitators for new sustainability projects.

\subsection{Practical and policy implications}

An increased understanding of the multifaceted roles played by champions and the dynamics of the championing process help policy-makers design effective programs and strategies to promote IS initiatives. From the policy perspective, it is important to consider the role of the institutional domain in IS emergence and explore how to link this domain to other champions. In this regard, local authorities can further facilitate and encourage IS emergence by reducing bureaucracy and providing necessary information and permissions. To enhance communication among potential partners, cross-industrial informal meetings and expert associations should be developed and promoted. In addition, education and awareness of such opportunities played huge role. Therefore, various learning resources about possibilities of IS should be developed. To further motivate potential partners, instrument such as standards and ecolabels could be also introduced.

Managers interested in pursuing IS emergence should realize the importance of champions in different organizations, levels and domains and let them lead their own projects. One individual may serve as a power, expert and collaborative champion, depending on the stage and domain of the process. Such individuals are important for all types of projects, but they are especially useful for IS emergence. As championing relies highly on individual agency, it might also cause overdependence and risk. Policymakers and managers should thus aim to institutionalize the role of championing and potentially aim to distribute the role to multiple individuals. A robust championing system could include a designated industrial symbiosis champion in all the key firms involved in the network.

\subsection{Limitations and suggestions for future research}

The main study focused on the progress of a single IS project from initiation to implementation. Studying IS in a region over a longer period would show how a region is impacted by successful IS and whether such projects catalyze new projects. Our findings also indicate that the broad legitimization stage can lead to international diffusion. Thus, studying cross-regional or cross-national championing work in more detail would be another fruitful avenue for future research.

The results of the pre-study suggest that several types of organizations can play a key role in championing IS. In the main study, we focused on an IS project that was selforganizing and largely driven by businesses, with the local authorities playing a supportive role. Future research could explore how the championing processes differ in projects with where the lead champions are different. For instance, the public sector has taken a more top-down role in facilitating industrial symbiosis in some regions, and such cases would be fruitful for comparative studies.

Overall, our findings highlight the importance of individual agency. However, further research is needed on the potential negative aspects of championing (e.g. overreliance on 
individual agency and network vulnerability). Future studies could also explore the relative importance of key antecedents for championing including organizational support, personal characteristics and social networks. 
Acknowledgements: We would like to thank the editors and the anonymous reviewers for the constructive comments throughout the process. Further, we would like to express our gratitude to the case companies and for our informants for granting the data access. The authors acknowledge Saint-Petersburg State University for research grants 16.42.969.2016, 16.42.971.2016, Russian Foundation for Basic Research for a research grant 17-07-00228 and the Finnish Funding Agency for Technology and Innovation (TEKES) via the DemaNET -project (grant 40477/11).

\section{References}

Ashton, W. (2008). Understanding the organization of industrial ecosystems: A social network approach. Journal of Industrial Ecology, 12, 34-51.

https://doi.org/10.1111/j.1530-9290.2008.00002.x

Ashton, W. S., \& Bain, A. C. (2012). Assessing the "short mental distance" in ecoindustrial networks. Journal of Industrial Ecology, 16(1), 70-82.

https://doi.org/10.1111/j.1530-9290.2011.00453.x

Baas, L. W. (2011). Planning and uncovering industrial symbiosis: comparing the Rotterdam and Östergötland regions. Business Strategy and Environment, 20, 428-440. https://doi.org/10.1002/bse.735

Behera, S. K., Kim, J. H., Lee, S. Y., Suh, S., Park, H. S. (2012). Evolution of "designed" industrial symbiosis networks in the Ulsan eco-industrial park: "Research and development into business" as the enabling framework. Journal of Cleaner Production, 29-30, 103-112. https://doi.org/10.1016/j.jclepro.2012.02.009

Boons, F. \& Spekkink, W. (2012). Levels of institutional capacity and actor expectations about industrial symbiosis: evidence from the Dutch stimulation program 1999-2004. Journal of Industrial Ecology, 16(1), 61-69. https://doi.org/10.1111/j.15309290.2011.00432.x

Boons, F., Chertow, M., Park, J., Spekkink, W., \& Shi, H. (2017). Industrial symbiosis dynamics and the problem of equivalence: proposal for a comparative framework.

Journal of Industrial Ecology, 21, 938-952. https://doi.org/10.1111/jiec.12468

Chakrabarti, A. K. (1974). The Role of Champion in Product Innovation. California Management Review, 17(2), 58-62. https://doi.org/10.2307/41164561

Chang, I.-C. C., Leitner, H., \& Sheppard, E. (2016). A Green Leap Forward? Eco-State Restructuring and the Tianjin-Binhai Eco-City Model. Regional Studies, 50, 929-943. https://doi.org/10.1080/00343404.2015.1108519

Chertow, M., \& Ehrenfeld, J. (2012). Organizing Self-Organizing Systems: Toward a Theory of Industrial Symbiosis. Journal of Industrial Ecology, 16(1), 13-27. https://doi.org/10.1111/j.1530-9290.2011.00450.x

Chertow, M., \& Miyata, Y. (2011). Assessing Collective Firm Behavior: Comparing Industrial Symbiosis with Possible Alternatives for Individual Companies in Oahu, Hawaii, Business. Business Strategy and the Environment, 20(4), 266-280.

https://doi.org/10.1002/bse.694 
Chertow, M. (2000). Industrial symbiosis: Literature and taxonomy. Annual Review of Energy and Environment, 25, 313-337.

https://doi.org/10.1146/annurev.energy.25.1.313

Deutz, P., \& Gibbs, D. (2008). Industrial ecology and regional development: Ecoindustrial development as cluster policy. Regional Studies, 42, 1313-1328. https://doi.org/10.1080/00343400802195121

Doménech, T. \& Davies, M. (2011). The role of embeddedness in industrial symbiosis networks: phases in the evolution of industrial symbiosis networks. Business Strategy and Environment, 20(5), 281-296. https://doi.org/10.1002/bse.695

Eriksson, P., \& Kovalainen, A. (2008). Qualitative Methods in Business Research. SAGE, Business \& Economics. https://doi.org/10.4135/9780857028044

Fichter, K. (2009). Innovation communities: the role of networks of promotors in Open Innovation. $R \& D$ Management, 39, 357-371. https://doi.org/10.1111/j.14679310.2009.00562.x

Foss, N. J., \& Saebi, T. (2017). Fifteen years of research on business model innovation: how far have we come, and where should we go? Journal of Management, 43(1), 200227. https://doi.org/10.1177/0149206316675927

Gibbs, D., Deutz, P., \& Proctor, A. (2005). Industrial ecology and eco-industrial development: A potential paradigm for local and regional development?. Regional Studies, 39(2), 171-183. http://dx.doi.org/10.1080/003434005200059959

Gibbs, D., \& Lintz, G. (2016). Editorial: Environmental Governance of Urban and regional Development - Scales and Sectors, Conflict and Cooperation. Regional Studies, 50(6), 95-928. https://doi.org/10.1080/00343404.2015.1110569

Gibbs, D., \& O'Neil, K. (2017). Future green economies and regional development: a research agenda. Regional Studies, 51(1), 161-173.

https://doi.org/10.1080/00343404.2016.1255719

Glaser, B. G., \& Strauss, A. L. (1999). The Discovery of Grounded Theory: Strategies for Qualitative Research. New Brunswick: Aldine Transaction Publishers.

Hauschildt, J. \& Gemunden, H. (1999). Promotoren - Champions der Innovation [Promotors - champions of innovation]. Wiesbaden: Gabler.

Henderson, R. M., \& Clark, K. B. (1990). Architectural innovation: The reconfiguration of existing product technologies and the failure of established firms. Administrative Science Quarterly, 35(1), 9-30. https://doi.org/10.2307/2393549

Hewes, A. K., \& Lyons, D. I. (2008). The humanistic side of eco-industrial parks: Champions and the role of trust. Regional Studies, 42, 1329-1342.

https://doi.org/10.1080/00343400701654079 
Howell, J. M., \& Higgins, C. M. (1990). Champions of change: Identifying, understanding and supporting champions of technological innovations. Organizational Dynamics, 19, 40-54. https://doi.org/10.1016/0090-2616(90)90047-S

Isenmann, R. (2002). Further Efforts to Clarify Industrial Ecology's Hidden Philosophy of Nature. Journal of Industrial Ecology, 6, 27-48. doi:10.1162/108819802766269520

Lacy, P., \& Rutqvist, J. (2016). Waste to Wealth: The Circular Economy Advantage. Springer.

Klerkx, L., \& Aarts, N. (2013). The interaction of multiple champions in orchestrating innovation networks: Conflicts and complementarities. Technovation, 33(6-7), 193210. https://doi.org/10.1016/j.technovation.2013.03.002

Klooster, D., \& Mercado-Celis, A. (2016). Sustainable Production Networks: Capturing Value for Labour and Nature in a Furniture Production Network in Oaxaca, Mexico. Regional Studies, 50, 1889-1902. https://doi.org/10.1080/00343404.2015.1071915

Lervik, J. E. (2011). The Single MNC as a Research Site. In R. Piekkari \& C. Welch (Eds), Rethinking the Case Study in International Business and Management Research (pp. 229-250). Cheltenham: Edward Elgar.

https://doi.org/10.4337/9780857933461.00022

Liu, C., Ma, C., \& Zhang, K. (2012). Going beyond the sectoral boundary: a key stage in the development of a regional industrial ecosystem. Journal of Cleaner Production, 22(1), 42-49. https://doi.org/10.1016/j.jclepro.2011.09.022

Lombardi, D. R., \& Laybourn, P. (2012). Redefining industrial symbiosis. Journal of Industrial Ecology, 16, 28-37. https://doi.org/10.1111/j.1530-9290.2011.00444.x

Mirata, M., \& Emtairah, T. (2005). Industrial symbiosis networks and the contribution to environmental innovation: the case of the Lanskrona industrial symbiosis programme. Journal of Cleaner Production, 13(10-11), 993-1002. https://doi.org/10.1016/j.jclepro.2004.12.010

Mulrow, J.S., Derrible, S., Ashton, W.S., \& Chopra, S.S. (2017). Industrial symbiosis at the facility scale. Journal of Industrial Ecology, 21, 559-571.

https://doi.org/10.1111/jiec.12592

Paquin, R. L., \& Howard-Grenville, J. (2012). The evolution of facilitated industrial symbiosis. Journal of industrial Ecology, 16(1), 83-93. https://doi.org/10.1111/j.15309290.2011.00437.x

Paquin, R. L., \& Howard-Grenville, J. (2013). Blind marriages, blind dates, and arranged marriages: longitudinal processes of network orchestration. Organizational Studies, 34(11), 1623-1653. https://doi.org/10.1177/0170840612470230

Rothwell, R. (1992). Successful industrial innovation: critical factors for the 1990s. $R \& D$ Management, 22, 221-238. https://doi.org/10.1111/j.1467-9310.1992.tb00812.x 
Salmi, O., \& Toppinen, A. (2007). Embedding science in politics: "complex utilization" and industrial ecology as models of natural resource use. Journal of Industrial Ecology, 11(3), 93-111. https://doi.org/10.1162/jiec.2007.1256

Schon, D. A. (1963). Champions for radical new inventions. Harvard Business Review, $41,77-86$.

Taddeo, R., Simboli, A., \& Morgante, A. (2012). Implementing eco-industrial parks in existing clusters: Findings from a historical Italian chemical site. Journal of Cleaner Production, 33, 22-29. https://doi.org/10.1016/j.jclepro.2012.05.011

Truffer, B., \& Coenen, L. (2012). Environmental Innovation and Sustainability Transitions in Regional Studies. Regional Studies, 46, 1-21.

https://doi.org/10.1080/00343404.2012.646164

Tudor, T., Adam, E., \& Bates, M. (2007). Drivers and limitations for the successful development and functioning of EIPs (eco-industrial parks): A literature review. Ecological Economics, 61, 199-207. https://doi.org/10.1016/j.ecolecon.2006.10.010

Walls, J. L., \& Paquin, R. L. (2015). Organizational Perspectives of Industrial Symbiosis: A Review and Synthesis. Organization \& Environment, 28(1), 32-53. https://doi.org/10.1177/1086026615575333

Witte, E. (1973). Organisation für Innovationsentscheidungen - Das Promotorenmodell [Organization for innovation decisions - the promoter model]. Göttingen: Schwart.

Yin, R. K. (2014). Case study research: Design and methods (5th ed.). Thousand Oaks, CA: SAGE Publications. 